\title{
Renal Tubular Effects of Chronic Phosphate Depletion
}

\author{
Stanley Goldfarb, George R. Westby, Martin Goldberg, and Zalman S. Agus \\ From the Renal Electrolyte Section, Department of Medicine, Hospital of the University of \\ Pennsylvania, Philadelphia, Pennsylvania 19104
}

A B S T R A C T The effects of chronic phosphate depletion on renal tubular function were evaluated by micropuncture and free water clearance studies in the dog. Proximal tubular punctures demonstrated that chronic hypophosphatemia led to a reduction in ratio of tubular fluid to plasma inulin in late superficial tubules from $1.59 \pm 0.08$ in control animals to $1.29 \pm 0.06$ in phosphate-depleted dogs, with proportional inhibition of calcium and sodium reabsorption. The chronic decrease in proximal tubular fluid reabsorption was confirmed by the analysis of sustained water diuresis in conscious, phosphate-depleted dogs, before and after repletion of body $\mathrm{PO}_{4}$ stores, and in control animals. Urine flow rate/100 ml glomerular filtration rate (V/GFR) was significantly higher in $\mathrm{PO}_{4}$ depletion than control $(15.8 \pm 1.1$ vs. $10.7 \pm 0.82)$. In addition, acetazolamide infusion did not increase V/GFR in phosphate-depleted dogs $(15.8 \pm 1.1$ vs. $17.16 \pm 0.9$ ), supporting the conclusion that inhibition of proximal tubular fluid reabsorption was responsible for the elevated urine flow rate. $\mathrm{PO}_{4}$ repletion over 5 days reduced V/GFR to $9.2 \pm 0.7$ despite no change in urine osmolality and no change in GFR, further suggesting a specific reversible alteration in proximal tubular reabsorption in phosphate depletion.

Although hypercalciuria was a constant finding in phosphate depletion (fractional excretion of calcium of $2.04 \pm 0.4 \%$ vs. $0.47 \pm 0.13 \%$ in controls), the enhanced distal delivery of calcium was not a crucial factor; acute phosphate infusion reduced urinary calcium excretion to control values without affecting the reduced proximal tubular reabsorption in either intact or thyroparathyroidectomized phosphate-depleted dogs. The change in distal nephron calcium reabsorp-

This work was presented in part at the National Meeting of the American Federation for Clinical Research, Atlantic City, N. J., May 1976.

Dr. Agus was a Clinical Investigator of the Veterans Administration; Dr. Goldfarb is a Research and Education Associate of the Veterans Administration; and Dr. Westby was a Fellow of the National Kidney Foundation.

Received for publication 13 July 1976 and in revised form 22 December 1976. tion was independent of parathyroid hormone (PTH) levels since infusion of PTH failed to alter urinary calcium excretion.

We conclude that chronic phosphate depletion leads to a reversible, sustained inhibition in proximal tubular reabsorptive function as well as a specific decrease in distal nephron calcium reabsorption. This latter reabsorptive defect is sensitive to phosphate infusion but not corrected by PTH.

\section{INTRODUCTION}

Chronic phosphate depletion produces alterations in function of many different organ systems. Previous studies have documented a series of disturbances in renal tubular function including a marked hypercalciuria (1-3), as well as lowered tubular maximum $(\mathrm{Tm})^{1} \mathrm{HCO}_{3}(4)$, and $\mathrm{Tm}$ glucose (5). Although these observations remain controversial, they are suggestive of disturbances in proximal tubular reabsorption. The intrarenal mechanism and sites of the altered calcium transport in this syndrome have not yet been clarified. The hypercalciuria could result from either a specific inhibitory effect of phosphate depletion upon calcium transport in the distal nephron, or from a generalized, nonspecific decrease in proximal tubular reabsorption which would in turn produce a delivery of calcium in excess of distal nephron reabsorptive capacity. The presumed absence of parathyroid hormone in this syndrome could produce increased calcium excretion either alone or in combination with alteration in tubular calcium transport.

The present series of experiments in chronically phosphate-depleted dogs was designed to investigate these problems by first characterizing the state of proximal tubular reabsorption and then evaluating the

\footnotetext{
${ }^{1}$ Abbreviations used in this paper: $\mathrm{CH}_{2} \mathrm{O}$, free water clearance; Cosm, osmolar clearance; CPD, chronic phosphate depletion; GFR, glomerular filtration rate; $\mathrm{PTH}$, parathyroid hormone; TF/P, ratio of tubular fluid to plasma; TF/UF, ratio of tubular fluid to ultrafilterable plasma; Tm, tubular maximum; TPTX, thyroparathyroidectomized; V, urine flow rate $(\mathrm{ml} / \mathrm{min})$.
} 
roles of distal nephron calcium delivery and parathyroid hormone secretion in the hypercalciuria of phosphate depletion.

\section{METHODS}

Female mongrel dogs weighing between 9 and $11 \mathrm{~kg}$ were studied either with micropuncture techniques or during sustained water diuresis in the conscious state as follows.

\section{Micropuncture studies}

Hydropenic fasted animals were anaesthetized with 20 $\mathrm{mg} / \mathrm{kg}$ intravenous sodium pentobarbital and received supplemental doses as required. The animals were intubated and ventilated with a Harvard respirator (Harvard Apparatus Co., Inc., Millis, Mass.). Surgical preparation of the animals for clearance and micropuncture studies was performed as previously described from this laboratory (6). Priming doses of $\left[{ }^{3} \mathrm{H}\right]$ inulin, $100 \mu \mathrm{Ci} / \mathrm{kg}$ were given followed by sustaining infusions of inulin in $0.9 \%$ saline at a rate of $0.5 \mathrm{ml} / \mathrm{min}$. Three to six late proximal tubules were selected for puncture using Lissamine Green transit time. The last appearance of dye in tubular convolutions was taken as the end point. Punctures were obtained over a 60 -min period beginning 30-45 min after Lissamine Green injection.

\section{Study I. Effects of chronic phosphate depletion}

To characterize proximal tubular function, three groups of animals were studied as described above. To avoid systematic methodological errors, animals in the following three groups were studied randomly.

Group I. Seven dogs who had been maintained on standard laboratory show for at least $1 \mathrm{wk}$ served as a control for the micropuncture procedure itself.

Group II. 10 animals were studied after 6-8 wk of phosphate depletion produced by being fed $250 \mathrm{~g} /$ day of a basal diet and $100 \mathrm{ml} /$ day of aluminum hydroxide gel. The basal diet, (ICN Pharmaceuticals Inc., Life Sciences Group, Cleveland, Ohio) modified from Coburn and Massry (1), contained less than $50 \mathrm{mg}$ phosphate/kg of diet. Animals which did not spontaneously feed underwent gastric intubation. Serum phosphate was determined to be $1.5 \mathrm{mg} / \mathrm{dl}$ or lower in all animals 1 wk before their selection for study.

Group III. Seven animals received the basal lowphosphate diet which was supplemented with $100 \mathrm{mg} /$ day of neutral sodium phosphate (phospho-soda, C. B. Fleet Co., Inc., Lynchburg, Va.) for 4-6 wk. This group served as a control for any effects of chronic administration of the basal diet on renal function.

\section{Study II. Effects of acute phosphate infusion}

To determine the mechanisms by which acute phosphate repletion corrects the hypercalciuria of phosphate depletion, three groups of animals were studied. After collections of tubular fluid and initial whole kidney clearance determination as described above, an intravenous infusion of neutral sodium phosphate $\left(\mathrm{Na}_{2} \mathrm{HPO}_{4}: \mathrm{NaH}_{2} \mathrm{PO}_{4}, 4: 1, \mathrm{pH}\right.$ $7.4,300 \mathrm{mosmol} / \mathrm{kg}$ ) was begun at a rate of $33.6 \mu \mathrm{mol} / 0.32$ $\mathrm{ml}$ per min and continued for $75 \mathrm{~min}$. Recollection of tubular fluid was then performed as previously described (7) and repeat clearance studies were obtained while continuing the phosphate infusion. The following groups were studied:
Group IV. Six chronically phosphate-depleted animals prepared as described above.

Group V. Four chronically phosphate-depleted animals acutely thyroparathyroidectomized $90-120 \mathrm{~min}$ before beginning micropuncture studies.

Group VI. Six normal animals, maintained on a standard diet, were acutely thyroparathyroidectomized and then studied to serve as a control for the effects of $\mathrm{PO}_{4}$ infusion.

\section{Sustained water diuresis studies in conscious animals}

To relate observations made during the above series of micropuncture studies to whole kidney function, a series of studies during sustained water diuresis was performed in conscious dogs after phosphate depletion, chronic phosphate repletion, and parathyroid hormone administration. A series of similar studies was performed in normal diet dogs as controls.

Animals were fasted overnight but allowed free access to water. The next morning, a no. 18 French intravenous catheter was placed in the external jugular vein for blood sampling and a no. 20 French intravenous catheter was inserted into a cephalic vein for infusion of solution. The urinary bladder was catheterized with a no. 12 French Foley catheter. The animals were then given $20 \mathrm{ml} / \mathrm{kg}$ body wt of tap water by orogastric tube, and infusions of inulin in $0.9 \%$ saline were begun at a rate of $0.5 \mathrm{ml} / \mathrm{min}$ with concentrations of inulin calculated to achieve plasma levels of approximately $25 \mathrm{mg} / \mathrm{dl}$. A solution of $2.5 \%$ dextrose was then begun at a rate of $5 \mathrm{ml} / \mathrm{min}$ for $60 \mathrm{~min}$ and was adjusted to match urine flow rate. When urine flow was stable (urine flow rate for three consecutive 10-min collection periods within $\pm 10 \%$ ) and urine osmolality was less than $60 \mathrm{mosmol} / \mathrm{kg}$, three 20 -min collections of urine were obtained. After the 60-min control period, each animal received an infusion of $5 \mathrm{mg} / \mathrm{kg}$ acetazolamide over $5 \mathrm{~min}$ and another three 20-min collections were performed. Blood samples for insulin, sodium, calcium, phosphate, and osmolality were obtained at 30 -min intervals before, during, and at the conclusion of the study. Two basic protocols were used.

\section{Study III. Effects of chronic phosphate depletion and chronic repletion}

Group VII. Four normal dogs maintained on standard laboratory chow for $2 \mathrm{wk}$ before study were studied during sustained water diuresis and acetazolamide infusion as described. After completion of this study, the animals were maintained on a normal diet for 5-7 days and then restudied using the same protocol. This group provides normal values for this study and also serves as a control for stability over a l-wk period.

Group VIII. Four dogs, chronically phosphate depleted as described above were studied during water diuresis. After completion of the studies, each animal was administered $1 \mathrm{~g}$ of phosphate as neutral sodium phosphate for 5 days while maintained on the basal low $\mathrm{PO}_{4}$ diet. After repletion of phosphate, these animals were restudied during water diuresis and acetazolamide infusion.

\section{Study IV. Effects of PTH infusion}

Group IX. Six chronically phosphate-depleted dogs underwent sustained water diuresis as described above, although a urine osmolality of less than $60 \mathrm{mosmol} / \mathrm{kg}$ was not a prerequisite for completion of these studies. After 
TABLE I

Clearance and Micropuncture Data in Phosphate-Depleted and Control Dogs*

\begin{tabular}{|c|c|c|c|c|c|c|c|c|c|c|c|}
\hline & \multicolumn{6}{|c|}{ Clearance } & \multicolumn{5}{|c|}{ Proximal tubule } \\
\hline & $\mathrm{C}_{\text {In }}$ & $\mathrm{UF}_{\mathrm{P} / 4}$ & $\mathrm{UF}_{\mathrm{Ca}^{++}}$ & $\mathrm{C}_{\mathrm{Na}} / \mathrm{C}_{\text {In }}$ & $\mathrm{C}_{\mathrm{C} \mathrm{d}} / \mathrm{C}_{\mathrm{ln}}$ & $\mathrm{C}_{\mathrm{pp},} / \mathrm{C}_{\mathrm{ln}}$ & $\mathrm{TF} / \mathrm{P}_{\mathrm{In}}$ & $\mathrm{TF} / \mathrm{P}_{\mathrm{Na}}$ & $\mathrm{TF} / \mathrm{UF}_{\mathrm{Ca}^{+}}{ }^{++}$ & $\mathrm{FR}_{\mathrm{Na}}$ & $\mathrm{FR}_{\mathrm{fa}}$ \\
\hline & $\mathrm{ml} / \mathrm{min}$ & $m g / d l$ & meqliter & & $\%$ & & & & & & $\%$ \\
\hline \multicolumn{12}{|c|}{ Group I, normal diet controls, $n=7$} \\
\hline Mean & 16.1 & 4.7 & 2.99 & 0.28 & 0.47 & 3.23 & 1.59 & 0.98 & 0.98 & 34 & 37 \\
\hline SEM & 2.1 & 0.5 & 0.88 & 0.13 & 0.13 & 0.55 & 0.08 & 0.03 & 0.04 & 3 & 5 \\
\hline \multicolumn{12}{|c|}{ Group II, CPD, $n=16$} \\
\hline Mean & 13.0 & 1.2 & 2.92 & 0.50 & 2.04 & 0.38 & 1.29 & 0.99 & 1.05 & 17 & 16 \\
\hline SEM & 0.9 & 0.2 & 0.03 & 0.11 & 0.44 & 0.14 & 0.06 & 0.06 & 0.04 & 4 & 6 \\
\hline$P$ value & NS & $<0.01$ & NS & $<0.02$ & $<0.02$ & $<0.025$ & $<0.01$ & NS & NS & $<0.01$ & $<0.01$ \\
\hline \multicolumn{12}{|c|}{ Group III, supplemented low phosphate diet, $n=7$} \\
\hline Mean & 16.0 & 7.0 & 3.07 & 0.11 & 0.44 & 7.14 & 1.55 & 0.99 & 1.06 & 34 & 32 \\
\hline SEM & 1.5 & 0.5 & 0.02 & 0.02 & 0.08 & 3.7 & 0.06 & 0.05 & 0.05 & 2 & 3 \\
\hline$P$ value & NS & $<0.01$ & NS & NS & NS & NS & NS & NS & NS & NS & NS \\
\hline
\end{tabular}

${ }^{*} \mathrm{C}_{\mathrm{In}}, \mathrm{C}_{\mathrm{Na}}, \mathrm{C}_{\mathrm{Ca}}, \mathrm{C}_{\mathrm{PO}_{4}}$, clearance of inulin, sodium, calcium and phosphate in the micropuncture kidney respectively; $\mathrm{C}_{\mathrm{Na}} / \mathrm{C}_{\mathrm{In}}, \mathrm{C}_{\mathrm{Ca}} / \mathrm{C}_{\mathrm{In}}$, and $\mathrm{C}_{\mathrm{PO}} / \mathrm{C}_{\mathrm{In}}$, fractional excretion of sodium, calcium and phosphate. $\mathrm{UF}_{\mathrm{PO}_{4}}$ and $\mathrm{UF}_{\mathrm{Ca}^{++}}$, concentration of plasma ultrafilterable calcium and phosphate, respectively. $T F / \mathrm{P}_{\mathrm{In}}$ and $\mathrm{TF} / \mathrm{P}_{\mathrm{Na}}$ refer to ratio of tubular fluid to plasma inulin and sodium concentrations and $\mathrm{TF} / \mathrm{UF}_{\mathrm{Ca}^{++}}$, the ratio of tubular fluid to plasma ultrafilterable calcium. $\mathrm{FR}$, fractional sodium and calcium reabsorption to the point of puncture in the proximal tubule calculated as $1-\left(\mathrm{TF} / \mathrm{P}_{\mathrm{Na}}\right) /\left(\mathrm{TF} / \mathrm{P}_{\mathrm{In}}\right)$ and 1 $-\left(\mathrm{TF} / \mathrm{UF}_{\mathrm{Ca}^{++}}\right) /\left(\mathrm{TF} / \mathrm{P}_{\mathrm{In}}\right) . P$ value refers to the significance of the difference of the mean when compared to group $\mathrm{I}$.

three 20-min control collection periods during a steady state, highly purified parathyroid hormone (Wilson Laboratories, Chicago, Ill., 1,100 U/mg) was infused at a rate of $60 \mathrm{U} / \mathrm{h}$, and 20 -min urine collections were continued for $120 \mathrm{~min}$.

\section{Analytical techniques}

Urine inulin, sodium, phosphate, and calcium, and serum ultrafiltrable calcium, phosphate, inulin, and sodium were measured as previously described (7). $\left[{ }^{3} \mathrm{H}\right]$ Inulin activity in tubular fluid, urine, and plasma was determined in a Packard liquid scintillation spectrometer (Packard Instrument Co., Inc., Downers Grove, Ill.) (6). Tubular fluid concentration of sodium and calcium was determined by electron microprobe analysis as previously described (6). Osmolality was measured with an osmometer (Osmette Precision Systems, Inc., Sudbury, Mass.).

The clearances of inulin, calcium, sodium, and phosphate were calculated in the usual manner. Osmolar clearance (Cosm) was calculated with the following formula: Cosm $=$ Uosm $\times$ V/Posm where Uosm $=$ osmolality of the urine (milliosmoles per kilogram of water), Posm $=$ osmolality of the serum (milliosmoles per kilogram of water), and $\mathrm{V}=$ urine flow rate (milliliters per minute). Free water clearance $\left(\mathrm{CH}_{2} \mathrm{O}\right)$ was calculated from the following formula: $\mathrm{CH}_{2} \mathrm{O}$ $=\mathrm{V}-$ Cosm.

Statistical analyses were performed utilizing Student's $t$ test for paired or nonpaired variables where appropriate.

\section{RESULTS}

\section{Micropuncture studies}

Effects of chronic phosphate depletion. The results of the clearance and micropuncture data from groups I-III are depicted in Table I. Since the control collection period of group II and IV animals represented studies in identically prepared animals, the control period of these two groups were pooled for purposes of comparison to normophosphatemic animals. Chronic phosphate depletion (group II) produced significant hypophosphatemia $\left(\mathrm{P}_{\mathrm{PO}_{4}}=1.24 \pm 0.21\right.$ $\mathrm{mg} / \mathrm{dl}$ ) and an increase in fractional calcium excretion to $2.04 \pm 0.44 \%$ whereas both glomerular filtration rate and plasma ultrafiltrable calcium were unchanged compared to normophosphatemic animals in groups I and III. There was also a slight increase in fractional excretion of sodium to $0.50 \pm 0.11 \%$. Fractional excretion of phosphate was reduced in phosphatedepleted animals to $0.38 \pm .14 \%$ of filtered phosphate compared to either group I or II animals. In the proximal tubule, ratio of tubular fluid to plasma (TF/P)inulin was markedly reduced during phosphate depletion to $1.29 \pm 0.06$ compared to $1.59 \pm 0.08$ in group I (Fig. 1) whereas ratio of tubular fluid to ultrafilterable plasma (TF/UF) Ca and TF/P Na were not different from the control group. Therefore, chronic phosphate depletion reduced the percentage of fractional reabsorption of sodium $(17 \pm 4 \%)$ and calcium $(16 \pm 6 \%)$ in proportion to the decrease in fluid transport in the proximal tubule. A comparison of the data from groups I and III revealed that other than an increase in serum phosphate, there were no effects of the low phosphate diet with phosphate supplement. Thus, whereas serum phosphate rose to $7.0 \pm 0.52 \mathrm{mg} / \mathrm{dl}$ in group III dogs, there were no differences either in the clear- 
ances of inulin, sodium, calcium, or phosphate, or in the proximal tubular reabsorption of sodium, water, or calcium between the two normophosphatemic groups.

Effects of acute phosphate infusion. The data from the recollection micropuncture experiments in groups IV-VI are presented in Table II, as the mean \pm SEM of data before (control) and after infusion of neutral sodium phosphate (recollection). Acute intravenous infusion of phosphate to chronically phosphate-depleted dogs produced a small decrease in both glomerular filtration rate (GFR) and fractional excretion of sodium whereas ultrafilterable plasma phosphate concentration rose significantly from $1.15 \pm 0.39$ to $4.75 \pm 0.82 \mathrm{mg} / \mathrm{dl}$. Fractional excretion of calcium fell markedly from $2.08 \pm 0.61$ to $0.32 \pm 0.08 \%$. Despite the rise in serum phosphate concentration, urinary phosphate excretion remained less than $0.5 \%$ of filtered load. In the proximal tubule, however, there were no changes in the fractional reabsorption of fluid, sodium, or calcium after intravenous phosphate. To determine if parathyroid hormone secretion was an important determinant of the decrease in calcium excretion associated with phosphate infusion, studies were repeated in thyroparathyroidectomized dogs. Infusion of phosphate to chronically phosphate-depleted, acutely thyroparathyroidectomized (TPTX) dogs (group V) did not change either GFR or fractional excretion of sodium, although plasma phosphate rose to $2.45 \pm 0.51$ from 0.8 $\pm 0.14 \mathrm{mg} / \mathrm{dl}$. Fractional excretion of phosphate was extremely low but fell even further to $0.35 \pm 0.14 \%$

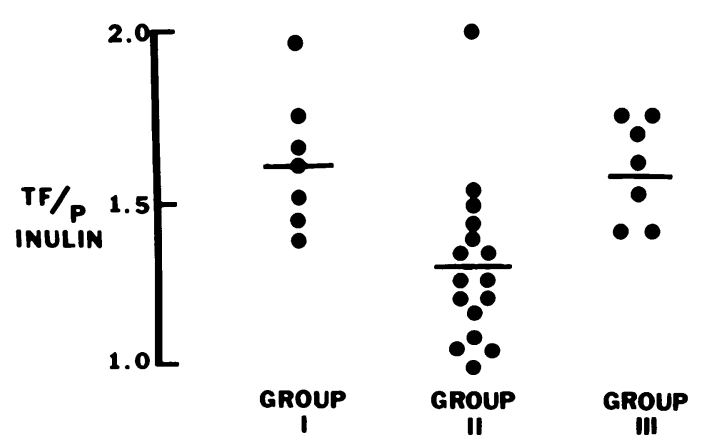

FIGURE $1 \mathrm{TF} / \mathrm{P}$ inulin in late, superficial proximal tubules in normal diet controls (group I), chronic phosphate depletion (group II), and low phosphate diet with phosphate supplements (group III). Each point represents the mean value of three to six tubules in each dog; the horizontal bar represents the mean value for each group.

after intravenous phosphate infusion. Fractional excretion of calcium fell significantly to $0.44 \pm 0.13$ from $2.20 \pm 0.97 \%$, similar to the changes observed in the group IV animals. In the proximal tubule there was again no alteration in fractional reabsorption of either sodium or calcium although serum ultrafilterable $\mathrm{Ca}^{++}$was lowered by the phosphate infusion. Infusion of phosphate to normophosphatemic acutely TPTX animals (group VI) produced no significant change in GFR, or fractional excretion of sodium or calcium. Ultrafilterable plasma phosphate increased from $6.06 \pm 0.84$ to $9.45 \pm 0.84 \mathrm{mg} / \mathrm{dl}$ and ultrafilterable calcium fell slightly from $3.02 \pm 0.07$ to $2.68 \pm 0.05$ $\mathrm{meq} / \mathrm{liter}$. As a result of this elevation in plasma ultra-

TABLE II

Effects of Intravenous Phosphate Infusion*

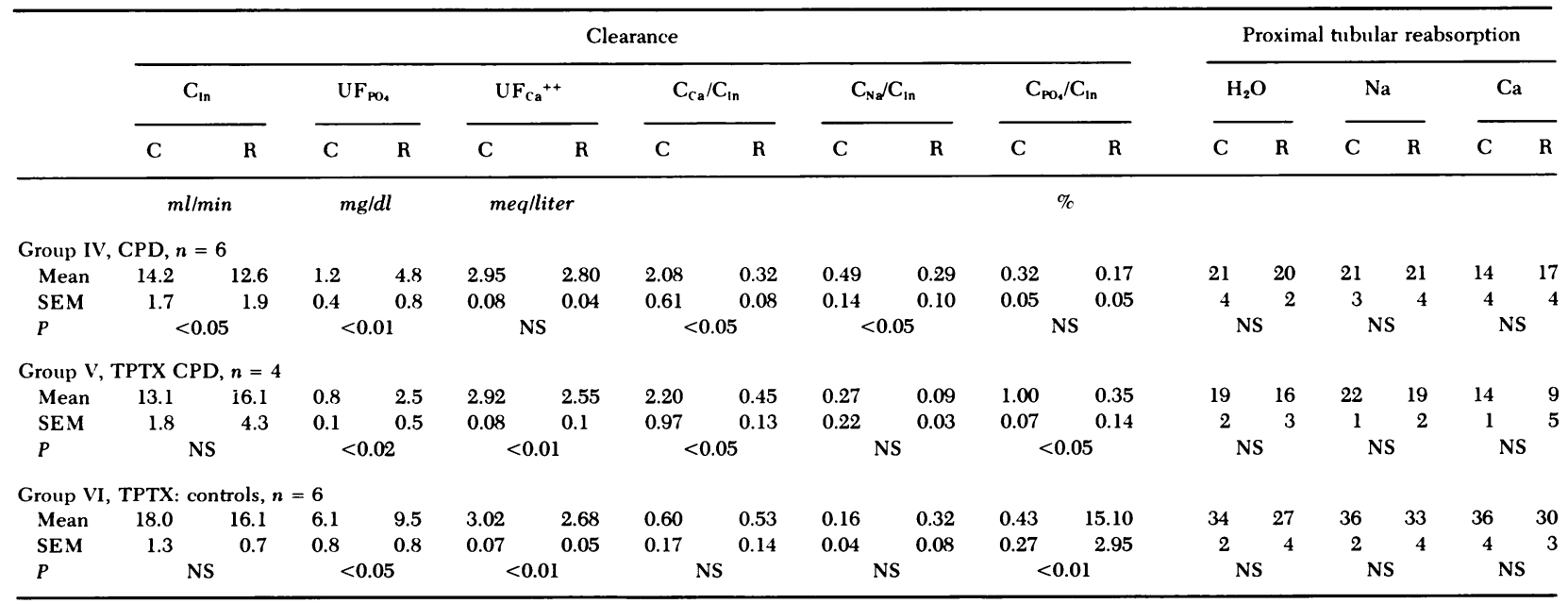

* $\mathrm{C}$, mean of clearance and micropuncture data simultaneously obtained during control period. $\mathrm{R}$, mean of recollection clearance and micropuncture data obtained 75 min after initiation of intravenous phosphate infusion. All clearance data represent values from micropunctured kidney. Proximal tubule reabsorption of water to the point of puncture is calculated as 1-(plasma/tubular fluid) inulin.

Remainder of abbreviations as in Table I. $P$ value refers to significance of difference of means between recollection period and control period in each group. 
filterable phosphate, the percentage of fractional excretion of phosphate rose from $0.43 \pm 0.27$ to $15.10 \pm 2.95 \%$ of filtered load. In the proximal tubule, there were no significant changes in the fractional reabsorption of sodium, calcium, or fluid.

\section{Sustained water diuresis studies}

Effects of chronic phosphate depletion and repletion. To determine the significance of micropuncture data from superficial nephrons in relation to whole kidney proximal tubular reabsorptive function, a series of studies was performed in conscious animals during sustained water diuresis. The data obtained in normal control animals (group VII) and chronically phosphate-depleted dogs (before and after dietary repletion) (group VIII A and B) are presented in Table III. Cosm, V, $\mathrm{CH}_{2} \mathrm{O}$, and Uosm, as well as urinary phosphate excretion, were not different during the control period. The serum phosphate concentration in these normal animals was lower than that found in nondiuretic, normal diet animals (group I), a probable consequence of the hypotonic glucose infusions necessary to produce a sustained water diuresis. The effects of this glucose infusion account for the low phosphate excretion in these animals (6). The fraction of the filtered load delivered out of the proximal tubule (V/GFR) and the fraction excreted as free water $\left(\mathrm{CH}_{2} \mathrm{O} / \mathrm{GFR}\right)$ however, were markedly increased in the phosphate-depleted dogs.

The effects of phosphate repletion were evaluated by restudying the depleted animals 5 days after dietary supplementation with $1 \mathrm{~g}$ of neutral sodium phosphate daily. As shown in Table III, phosphate repletion increased plasma ultrafilterable phosphate to $2.67 \pm 0.03$ from $0.36 \pm 0.03 \mathrm{mg} / \mathrm{dl}$. There was no change in GFR with repletion, and a significant fall in both $\mathrm{V}$ and $\mathrm{CH}_{2} \mathrm{O}$, as a fraction of the filtered load, to normal values. In contrast, there was no change in any parameter with restudy of the normal animals, indicating that correction of the abnormalities in proximal tubular delivery was not merely a function of the time interval between the repeat studies.

In Table III, the effects of acetazolamide infusion in the three groups is shown. After the control period, acetazolamide produces a marked rise in $\mathrm{V}, \mathrm{V}$ factored for GFR in normal diet animals, and in phosphate-depleted animals that have been repleted with oral phosphate. However, during phosphate depletion, this agent has no effect on $\mathrm{V}$ despite comparable urinary osmolality in each of the three experimental groups. As may be seen in Table III, when the period after acetazolamide is compared between normal, phosphate-repleted, and phosphatedepleted animals, the differences between groups with respect to $\mathrm{V}$ and $\mathrm{CH}_{2} \mathrm{O}$ are abolished. The only parameter which distinguishes phosphate-depleted animals from normophosphatemic animals after acetazolamide is a markedly lower serum ultrafilterable phosphate level.

Effects of parathyroid hormone (PTH) infusion. Table IV depicts the effects of the administration of highly purified PTH to six chronically phosphatedepleted dogs. The data are expressed as the mean \pm SEM of the clearance values $1 \mathrm{~h}$ before and $1-2 \mathrm{~h}$ after PTH infusion. There were no changes in GFR,

TABLE III

Studies during Sustained Water Diuresis and after Acetazolamide Infusion in Normal Controls and in Phosphate-Depleted Dogs before and after Phosphate Repletion*

\begin{tabular}{|c|c|c|c|c|c|c|c|c|c|c|c|c|c|c|c|}
\hline & & \multicolumn{2}{|c|}{$C_{l n}$} & \multicolumn{2}{|c|}{$U F_{P 14}$} & \multicolumn{2}{|c|}{ V } & \multicolumn{2}{|c|}{ Uosm } & \multicolumn{2}{|c|}{$V / C_{\text {In }}$} & \multicolumn{2}{|c|}{$\mathrm{CH}_{2} \mathrm{O} / \mathrm{C}_{\mathrm{In}}$} & \multicolumn{2}{|c|}{$U V_{P(1,}$} \\
\hline & & C & $\mathrm{ACZ}$ & C & $\mathrm{ACZ}$ & C & $\mathrm{ACZ}$ & C & $A C Z$ & C & $\mathrm{AC} Z Z$ & C: & ACZZ & $\mathrm{C}$ & $\mathrm{ACZ}$ \\
\hline & & \multicolumn{2}{|c|}{$\mathrm{ml} / \mathrm{min}$} & \multicolumn{2}{|c|}{$m g / d l$} & \multicolumn{2}{|c|}{$\mathrm{ml} / \mathrm{min}$} & \multicolumn{2}{|c|}{ mosmol/kg } & \multicolumn{2}{|c|}{$\%$} & \multicolumn{2}{|c|}{$\%$} & \multicolumn{2}{|c|}{$\mu g / m i n$} \\
\hline Group VII & Mean & 50.8 & $46.4 \ddagger$ & 2.7 & 3.1 & 5.3 & 7.1 & 46.2 & 8.5 .1 & 10.7 & 16.1 & 8.9 & 10.7 & 0.21 & 0.32 \\
\hline \multirow[t]{2}{*}{ Normal diet } & SEM & 7.5 & 5.1 & 0.2 & 0.1 & 0.5 & 0.5 & 4.7 & 4.2 & 0.8 & 0.9 & 0.8 & 0.4 & 0.05 & 0.01 \\
\hline & $P$ & \multicolumn{2}{|c|}{ NS } & \multicolumn{2}{|c|}{ NS } & \multicolumn{2}{|c|}{$<0.025$} & \multicolumn{2}{|c|}{$<0.001$} & \multicolumn{2}{|c|}{$<0.01$} & \multicolumn{2}{|c|}{ NS } & \multicolumn{2}{|c|}{ NS } \\
\hline Group VIII(A) & Mean & 31.7 & 28.9 & $\$ 0.4$ & 0.4 & 5.1 & 4.8 & 42.3 & 78.3 & $\$ 15.8$ & 17.1 & $\$ 13.4$ & 12.2 & 0.11 & 0.14 \\
\hline Phosphate & SEM & 3.9 & 3.2 & 0.03 & 0.02 & 0.9 & 0.6 & 3.7 & 4.1 & 1.1 & 0.9 & 0.9 & 0.7 & 0.01 & 0.02 \\
\hline depletion & $P$ & \multicolumn{2}{|c|}{ NS } & \multicolumn{2}{|c|}{ NS } & \multicolumn{2}{|c|}{ NS } & \multicolumn{2}{|c|}{$<0.001$} & \multicolumn{2}{|c|}{ NS } & \multicolumn{2}{|c|}{ NS } & \multicolumn{2}{|c|}{ NS } \\
\hline Group VIII(B) & Mean & 37.2 & 36.1 & 2.7 & 3.3 & 3.5 & 5.4 & 36.8 & 70.3 & ๆ9.2 & 14.1 & $\$ 8.4$ & 11.9 & 0.14 & 1.6 \\
\hline After & SEM & 2.2 & 1.5 & 0.1 & 0.15 & 0.4 & 0.6 & 4.3 & 4.3 & 0.7 & 0.2 & 0.9 & 1.8 & 0.04 & 1.4 \\
\hline $\begin{array}{l}\text { phosphate } \\
\text { repletion }\end{array}$ & $P$ & \multicolumn{2}{|c|}{ NS } & \multicolumn{2}{|c|}{$<0.05$} & \multicolumn{2}{|c|}{$<0.01$} & \multicolumn{2}{|c|}{$<0.001$} & \multicolumn{2}{|c|}{$<0.02$} & \multicolumn{2}{|c|}{ NS } & & \\
\hline
\end{tabular}

* $\mathrm{C}$, control period of water diuresis study. $\mathrm{ACZ}$, period of acetazolamide infusion. $\mathrm{V}$, urine flow rate; Uosm urine osmolality; $\mathrm{CH}_{2} \mathrm{O}$, clearance of solute free water, $\mathrm{UVPO}_{4}=$ urinary excretion of phosphate. $P$ refers to significance of difference between mean values before and after acetazolamide infusion in each group. I Refers to $P$ value less than $\mathbf{0 . 0 5}$ when compared to period after acetazolamide in group VIII phosphate-depleted animals.

$\$$ Refers to $P$ value of less than 0.01 compared to period before acetazolamide infusion in group VII normal diet animals or group VIII phosphate-repleted animals. $\|$ Refers to $P$ value less than 0.01 when compared to period after acetazolamide infusion of group VII normal diet or group VIII phosphate-repleted animals.

I Refers to $P$ value less than 0.01 when compared to control period before acetazolamide in group VIII phosphate-depleted animals. Each period before or after acetazolamide represents the mean value of three 20 -min clearance periods. 
ultrafilterable calcium, or phosphate concentration. There was a small natriuresis during the $2 \mathrm{nd} \mathrm{h}$ as fractional excretion of sodium rose from $0.49 \pm 0.21$ to $1.33 \pm 0.39 \%$ but fractional excretion of phosphate remained at markedly reduced levels despite the PTH infusion. The markedly increased fractional calcium excretion of $4.09 \pm 1.36$ tended to fall to $3.25 \pm 1.21$ during the 1 st $h$ and $3.91 \pm 1.35$ in the $2 n d h$. These changes however, were not statistically significant; thus, acute PTH infusion did not correct the hypercalciuria characteristic of chronic phosphate depletion when renal hemodynamic parameters were stable.

\section{DISCUSSION}

The results of the present study suggest that chronic phosphate depletion produces at least two independent effects upon renal tubular function: sustained inhibition of proximal tubular transport and decreased calcium reabsorption in the distal nephron which is independent of changes in PTH levels.

Earlier studies of the renal effects of chronic phosphate depletion (CPD) suggested that there might be alterations of some components of proximal tubular function in this condition. For example, the Tm for bicarbonate, primarily a proximal tubular function, has been shown to be significantly reduced in phosphate depletion. Although this was attributed to alterations in intracellular $\mathrm{pH}(4)$, reduction of proximal tubular sodium transport also would be associated with inhibition of bicarbonate reabsorption (9). Such a possibility has been supported by earlier clearance studies which suggested that CPD may lead to inhibition of sodium reabsorption in the proximal tubule of the dog (10). In addition, evidence for a decrease in $\mathrm{Tm}$ glucose has been obtained in phosphate depletion (5), compatible with the concept of a generalized decrease in proximal tubular function. Other investigators, however, have been unable to document this decrease in Tm glucose (11). As phosphate and glucose appear to compete for transport in the proximal tubule (6), it is possible that hypophosphatemia may enhance glucose transport and severe phosphate depletion may depress proximal function accounting for the discrepancy in the two studies $(5,11)$.

Our micropuncture data clearly suggest a reduction in superficial proximal tubular fluid transport in chronically phosphate-depleted animals when compared to controls. That this alteration is not due to some component of the diet other than phosphate depletion per se is demonstrated by the normal values for proximal tubular reabsorption which we obtained in the animals given the experimental diet supplemented with phosphate. However, there are several possible
TABLE IV Effects of PTH Infusion in CPD*

\begin{tabular}{lccc}
\hline & Control & 1st $\mathrm{h}$ & 2nd $\mathrm{h}$ \\
\hline $\mathrm{C}_{\mathrm{In}}, \mathrm{ml} / \mathrm{min}$ & $29.33 \pm 2.77$ & $30.13 \pm 2.58$ & $32.62 \pm 4.06$ \\
$\mathrm{UF}_{\mathrm{PO}}$, mg/dl & $0.5 \pm 0.12$ & $0.6 \pm 0.15$ & $0.75 \pm 0.10$ \\
$\mathrm{UF}_{\mathrm{Ca}^{++}, \text {meq/liter }}$ & $2.95 \pm 0.14$ & $2.90 \pm 0.13$ & $2.86 \pm 0.16$ \\
$\mathrm{C}_{\mathrm{Na}} / \mathrm{C}_{\mathrm{In}}, \%$ & $0.49 \pm 0.2$ & $0.51 \pm 0.1$ & $1.33 \pm 0.4 \ddagger$ \\
$\mathrm{C}_{\mathrm{Ca}} / \mathrm{C}_{\mathrm{In}}, \%$ & $4.09 \pm 1.4$ & $3.25 \pm 1.2$ & $3.91 \pm 1.4$ \\
$\mathrm{C}_{\mathrm{PO}} / \mathrm{C}_{\mathrm{In}}, \%$ & $1.07 \pm 0.16$ & $0.96 \pm 0.15$ & $0.88 \pm 0.19$
\end{tabular}

* Values are expressed as mean \pm SEM. Control refers to clearance periods during hour before PTH infusion. 1st and $2 \mathrm{nd} \mathrm{h}$ refer to data obtained during 1 st and $2 \mathrm{nd} h$ of infusion. $\ddagger=P<0.05$ compared to control.

objections to extrapolating a low $\mathrm{TF} / \mathrm{P}$ inulin ratio to indicate inhibition of proximal tubular fluid reabsorption. For example, if the tubular site of puncture was consistently earlier in chronically phosphatedepleted animals, TF/P inulin would be reduced, but fluid reabsorptive rate would be unaffected. The introduction of such observer bias or of a systematic error in the collection or analysis of tubular fluid samples was carefully avoided. Specifically, control animals in group I were studied in an alternating fashion with animals in groups II and IV (CPD).

In addition, recent studies have suggested that there are important electrophysiological (12), and therefore possibly reabsorptive, differences between superficial and juxtamedullary cortical nephrons. Thus, it may not be justified to extend observations from superficial nephrons to include the entire proximal tubule population. To circumvent these problems, we evaluated whole kidney segmental fluid transport utilizing $\mathrm{CH}_{2} \mathrm{O}$ studies. In these experiments, animals were evaluated after induction of CPD in a manner identical to the group II micropunctured animals. This series of water diuresis experiments was designed to verify the conclusions reached in the micropuncture studies.

Under conditions of sustained water diuresis and maximal vasopressin suppression, the ratio of $\mathrm{V}$ to GFR (V/GFR) has been used as an index of delivery of filtrate from the proximal tubule to the distal nephron $(13,14)$. During states in which distal nephron delivery of filtrate is enhanced, changes in $\mathrm{CH}_{2} \mathrm{O}$ /GFR may also reflect such an increased delivery if the solute reabsorptive function of distal nephron diluting sites is unimpaired (14). In our studies, CPD was associated with a significantly greater V/GFR and $\mathrm{CH}_{2} \mathrm{O}$ /GFR when compared to control animals with comparably low urine osmolality. Moreover, the reversibility of these abnormalities with dietary repletion of phosphate further supports the primary role of phosphate depletion in the genesis of the proximal 
tubular dysfunction. Such analyses during water diuresis have been used to evaluate the tubular sites of action of various drugs and physiological maneuvers (14). However, such studies have potential pitfalls in interpretation since a number of theoretical assumptions underlie their use. For example, an increased $\mathrm{V}$ during water diuresis does not necessarily imply decreased fluid reabsorption in the proximal tubule. It could indicate decreased water abstraction from the descending limb of Henle's loop and decreased nonantidiuretic hormone-dependent water reabsorption across the collecting duct epithelium. These two phenomena might occur if medullary solute concentration was "washed-out" by some experimental maneuver. Thus, it is possible that CPD could alter medullary solute accumulation and thereby lead to the increased V/GFR and $\mathrm{CH}_{2} \mathrm{O} / \mathrm{GFR}$ seen in the animals studied during sustained water diuresis. Also, if collecting duct permeability to water was decreased, diminution of "back flux" of water across this epithelium could be manifested as a rise in $\mathrm{V}$ and free water excretion. Thus, clearance studies alone although inferential, could not definitively identify the tubular sites of altered fluid reabsorption.

It is because of the possibility of alternate interpretations of such clearance data that the importance of the parallel series of micropuncture experiments becomes apparent. Two groups of phosphate-depleted animals were prepared in identical fashion and micropuncture was performed in one and the clearance studies in the other. This allowed direct comparison of parameters of proximal tubular function by two different experimental techniques and thereby facilitated specific interpretation of the observed data. Thus, whereas alternate explanations could be employed to analyze either micropuncture or clearance data alone, the combined experimental approach strongly supports the conclusion that inhibition of fluid reabsorption occurs in proximal convoluted tubules of the chronically phosphate-depleted dog.

The observations on the response in V/GFR and $\mathrm{CH}_{2} \mathrm{O}$ /GFR to acetazolamide infusion in phosphatedepleted animals further suggests inhibition of proximal tubular fluid reabsorption. Acetazolamide has been shown to specifically inhibit filtrate reabsorption in the proximal tubule through inhibition of carbonic anhydrase (8). This agent has been employed to evaluate segmental tubular function during water diuresis and consistently produces an increase in V/GFR and a variable increase in $\mathrm{CH}_{2} \mathrm{O} / \mathrm{GFR}$, confirming micropuncture studies which localize its site of action to the proximal tubule (8). In the present studies, acetazolamide produced no change in V/GFR in phosphate-depleted animals while significantly increasing this parameter in normal control and phosphate-repleted dogs. If the high rate of V/GFR seen in phosphate-depleted animals represents inhibition of proximal tubular fluid reabsorption, then infusion of an agent known also to inhibit proximal tubular reabsorption would be expected to produce little further effect. However, if medullary solute "washout" or decreased water permeability of the collecting duct was the mechanism of the increased V/GFR, an agent which leads to inhibition of proximal tubular fluid reabsorption would lead to a further rise in V/GFR as delivery to distal nephron sites increases. Thus, absence of such an effect of acetazolamide in phosphate-depleted dogs leads to verification of the conclusion that phosphate depletion produces inhibition of proximal tubular fluid reabsorption. Moreover, the analysis of free water excretion data demonstrate that acetazolamide infusion normalizes the large differences between hypophosphatemic and normophosphatemic controls further corroborating the assumption that the increased free water excretion in phosphate depletion is due to enhanced delivery of filtrate to the distal nephron sites of urinary dilution.

In addition, a recent observation from our laboratory supports the validity of the conclusion that increased V/GFR and $\mathrm{CH}_{2} \mathrm{O} / \mathrm{GFR}$ represent increased filtrate delivery from the proximal tubule and not wash out of medullary solute concentration. Maximum urine osmolality after $12 \mathrm{~h}$ of fluid deprivation in chronically phosphate-depleted rats was greater than $1,900 \mathrm{mosmol} / \mathrm{kg}$ and identical to normal controls. ${ }^{2}$ Thus, although no direct study of medullary solute gradients is available in chronic phosphate depletion, these data suggest that significant medullary washout is not a feature of phosphate depletion.

The present studies do not define the mechanism of the defect in proximal tubule reabsorptive function. A large body of information has accrued on the effects of phosphate depletion on red cells $(15,16)$, phagocytes (17), hepatocytes (18), skeletal muscle (19), and neural tissue (20). Generally, intracellular phosphate levels are low as are intracellular ATP levels (20). Thus, abnormalities seen in phosphate depletion have been attributed to deficiencies of cellular energy stores $(16,19)$. The possible role of similar abnormalities in the cellular metabolism of proximal tubular epithelia remains unknown. It is interesting however, that acute phosphate infusion in our studies did not correct the abnormality whereas dietary repletion restored proximal tubular reabsorption to

\footnotetext{
${ }^{2}$ Emmett, M., S. Goldfarb, Z. S. Agus, and R. Narins. Unpublished observations. Urine osmolality was $1,959 \pm 73$ mosmol/kg in five phosphate-depleted rats (3 wk of $0.03 \%$ phosphate diet) and 2,096 444 in five pair fed control diet animals $(P>0.3)$. Urine osmolality was determined after $1 \mathrm{U}$ pitressin tannate in oil intramuscularly after $12 \mathrm{~h}$ of fluid deprivation.
} 
normal values over 5 days. The infusion of phosphate in intact animals would be expected to produce an increase in PTH secretion (21). Thus, the failure of acute phosphate infusions to correct the defect in proximal tubular fluid and calcium reabsorption of phosphate depletion in this group could represent the simultaneous occurrence of two mutually antagonistic effects on the proximal tubule; phosphate repletion could act to normalize the reabsorptive defect found in phosphate depletion whereas an acute rise in PTH levels would lead to inhibition of proximal tubular fluid reabsorption (7). The studies in TPTX, phosphate-depleted dogs (group V) obviate this possibility. In these animals, acute phosphate infusion also failed to correct the altered proximal tubular reabsorption of calcium and fluid. It is also possible that other competitive factors were present to influence proximal reabsorption. For example, the small phosphate infusion could produce enough expansion of extracellular fluid volume to inhibit proximal fluid reabsorption whereas the correction of phosphate deficiency would now act to restore fluid reabsorption to normal. The net effect of these opposing factors could also result in no change from base line. The infusion of phosphate into TPTX normophosphatemic dogs however, did not produce a significant fall in $\mathrm{TF} / \mathrm{P}$ inulin, and therefore suggests that volume expansion was not produced by these infusions. On the other hand, whereas acute correction of the defect in proximal tubular function was not demonstrable in these micropuncture studies, chronic reversibility was clearly shown in animals repleted with oral phosphate supplements and studied by sustained water diuresis.

The mechanism of hypercalciuria with phosphate depletion has been studied in both man and experimental animals. Factors which could contribute to increased urinary calcium excretion include increase in filtered load, and (or) decreased proximal tubular reabsorption which would increase delivery of filtered calcium to the distal nephron. Calcium reabsorption in the distal nephron could be diminished by a decrease in circulating levels of PTH (22) with phosphate depletion or by a specific transport defect associated with phosphate depletion.

Our data suggest that neither an increase in filtered load nor increased delivery of filtrate out of the proximal tubule play an important role in producing hypercalciuria. These conclusions derive from the observation that the acute infusion of phosphate to chronically phosphate-depleted dogs abolished hypercalciuria but did not alter the massive delivery of calcium to the distal nephron. Since final urinary calcium excretion may be independent of distal nephron delivery, these data are more compatible with inhibition of some component of distal nephron cal- cium reabsorption by phosphate depletion as the mechanism of hypercalciuria. Enhanced intestinal calcium absorption and (or) increased bone resorption associated with phosphate depletion (3) would be expected to suppress secretion of PTH. Decreased circulating levels of PTH in this syndrome therefore, may represent a potential hormonal mechanism for the inhibition of distal nephron calcium transport. Previous studies evaluating this hypothesis have been inconclusive. For example, the administration of parathyroid extract to phosphate-depleted dogs reduced urinary calcium excretion but not to normal levels (1). This was interpreted as evidence for the presence of PTH-independent inhibition of calcium transport. However, parathyroid extract produces striking renal hemodynamic effects which could modify the hypocalciuric response to PTH. In our studies, the administration of highly purified PTH failed to lower fractional excretion of calcium to normal levels whereas GFR and filtered load of calcium were stable. On the other hand, as has been previously demonstrated (23), acute infusion of phosphate completely abolished the hypercalciuria in both intact and TPTX phosphate-depleted dogs. These data suggest that some component of calcium transport beyond the proximal tubule which is independent of PTH is altered by CPD to produce hypercalciuria. Our studies do not define the cellular mechanisms involved in this event. It is possible that the lack of a hypocalciuric response to PTH is the result of a deficit of some tubular constituent, such as phosphate, rather than a primary cellular resistance to the actions of the hormone but, again, the present data cannot resolve this question.

Previous studies have suggested that the inhibition of calcium transport produced by a decrease in serum phosphate is associated with a systemic rather than a direct renal effect (1). Although chronic expansion of the extracellular fluid volume produces hypercalciuria, it is unlikely that such a mechanism is operative in phosphate depletion since hypercalciuria persists when depleted animals are placed on a salt-free diet (1). Chronic metabolic acidosis also is associated with increased urinary calcium excretion (24). Previous studies have been unable to document consistent changes in acid-base status in phosphate depletion $(1,4)$, and measurement of arterial $\mathrm{pH}$ in our animals did not reveal evidence of metabolic acidosis. Studies in our laboratory in phosphate-depleted rats however, have documented the presence of a renal tubular acidosis which is masked by bicarbonate release from bone (25). It therefore remains possible that intracellular $\mathrm{pH}$ may be altered by phosphate depletion in the absence of overt changes in arterial $\mathrm{pH}$ and play a role in the development of hypercalciuria, analagous to the syndrome of 
incomplete renal tubular acidosis (26). Measurements with 55-dimethyl-2,4 oxazolidinedione however, have suggested an increase in muscle intracellular $\mathrm{pH}$ associated with phosphate depletion (4). Therefore, the role of changes in systemic acid-base balance in producing the hypercalciuria of phosphate depletion remains unclear. Other factors which may alter calcium transport and which remain to be defined include alterations of distal nephron tubular fluid $\mathrm{pH}$ by phosphate infusion, phosphate-induced changes in intracellular calcium concentration, or the possibility of a humoral factor which inhibits calcium reabsorption during phosphate depletion (27).

Although these studies were not designed to evaluate the renal handling of phosphate during CPD, several points do emerge from an analysis of the urinary excretion of phosphate in the various experimental groups. As has been previously shown, urinary phosphate excretion is extremely low in phosphatedepleted animals and may not rise with elevations in serum phosphate (28). Thus, in group IV micropuncture studies, the elevation of serum ultrafilterable phosphate from $1.2 \pm 0.4$ to $4.8 \pm 0.8 \mathrm{mg} / \mathrm{dl}$ produced no rise in the fractional excretion of filtered phosphate $(0.32 \pm 0.05-0.17 \pm 0.05 \%)$. After administration of PTH to chronic phosphate-depleted dogs (group IX), there was no increase in phosphate excretion. These results confirm previous observations of the effects of PTH on phosphate reabsorption in chronically phosphate-deprived animals (29). In general, the phosphatedepleted dog would appear to demonstrate resistance to both the phosphaturic and hypocalciuric effects of PTH.

In summary, our studies using both micropuncture and $\mathrm{CH}_{2} \mathrm{O}$ techniques have defined an effect of CPD on reabsorptive function in both the proximal tubule and distal nephron. The reabsorption of fluid, calcium, and sodium is significantly reduced in the proximal tubule but only calcium reabsorption is altered in the distal nephron, accounting for the hypercalciuria. The proximal tubular abnormality was not altered by acute phosphate infusion but responded to chronic repletion with dietary phosphate. Acute infusion of phosphate but not PTH corrects the hypercalciuria in both intact and TPTX dogs. Thus, alterations in phosphate balance independent of PTH modulate urinary calcium excretion by affecting calcium reabsorption in the distal nephron. The relevance of these observations to other models of hypercalciuria such as idiopathic hypercalciuria with hypophosphatemia in man (30) remains to be defined with careful studies of proximal tubular transport. In addition, the use of phosphate depletion as a model characterized by sustained inhibition of proximal tubular reabsorption may facilitate the study of the importance of the proximal tubule in various pathophysiological states of altered sodium balance.

\section{ACKNOWLEDGMENTS}

We would like to thank Dorothy Senesky, Mattie Davis, Marguerite LaPorta, Frances McKee, Sandra Markus, Carmen D’Angelo, Phyllis May, Marva Lee, and Freda Rappaport for technical assistance in performing the studies and for the laboratory analyses.

This work was supported by a research grant from the National Heart and Lung Institute, HL-00340, the Veterans Administration, and by a training grant from the National Institute of Arthritis, Metabolic and Digestive Diseases, 1 T32-AM-07006.

\section{REFERENCES}

1. Coburn, J. W., and S. G. Massry. 1970. Changes in sodium and urinary calcium during phosphate depletion: studies on mechanisms. J. Clin. Invest. 49: 1073-1087.

2. Day, H. G., and E. V. McCollum. 1939. Minearal metabolism, growth, and symptomatology of rats on a diet extremely deficient in phosphorus. J. Biol. Chem. 130: 269-283.

3. Lotz, M., E. Zisman, and F. C. Bartter. 1968. Evidence for a phosphorus-depletion syndrome in man. N. Engl. J. Med. 278: 409-415.

4. Gold, L. W., S. G. Massry, A. I. Arieff, and J. W. Coburn. 1973. Renal bicarbonate wasting during phosphate depletion. A possible cause of altered acid-base homeostasis in hyperparathyroidism. J. Clin. Invest. 52: 2556-2562.

5. Gold, L., S. G. Massry, and R. M. Friedler. 1976. Effect of phosphate depletion on renal glucose reabsorption. Clin. Res. 24: 400A. (Abstr.)

6. DeFronzo, R. A., M. Goldberg, and Z. S. Agus. 1976. The effects of glucose and insulin on renal electrolyte transport. J. Clin. Invest. 58: 83-90.

7. Agus, Z. S., J. B. Puschett, D. Senesky, and M. Goldberg. 1971. Mode of action of parathyroid hormone and cyclic adenosine $3^{\prime}, 5^{\prime}$-monophosphate on renal tubular phosphate reabsorption in the dog. J. Clin. Invest. 50: 617626.

8. Goldberg, M. 1973. The renal physiology of diuretics. Handb. Physiol. (Sect. 8. Renal Physiology): 1003-1031.

9. Kurtzman, N. A., M. G. White, P. W. Rogers, and J. J. Flynn III. 1972. Relationship of renal bicarbonate reabsorption and glomerular filtration rate to renal glucose reabsorption. J. Clin. Invest. 51: 127-133.

10. Gold, L. W., S. G. Massry, C. M. Rothman, and J. W. Coburn. 1973. Effect of phosphate depletion on renal handling of calcium and sodium. Clin. Res. 21: 282. (Abstr.)

11. Harter, H. R., A. Mercado, W. E. Rutherford, H. Rodriguez, E. Slatopolsky, and S. Klahr. 1974. Effects of phosphate depletion and parathyroid hormone on renal glucose reabsorption. Am. J. Physiol. 227: 14221427.

12. Jacobson, H. R., and J. P. Kokko. 1976. Intrinsic differences in various segments of the proximal convoluted tubule. J. Clin. Invest. 57: 818-825.

13. Seldin, D. W., J. M. Rosin, and F. C. Rector, Jr. 1975. Evidence against bicarbonate reabsorption in the ascending limb, particularly as disclosed by free-water clearance studies. Yale J. Biol. Med. 48: 337-347. 
14. Seldin, D. W., and F. C. Rector, Jr. 1973. Evaluation of clearance methods for localization of site of action of diuretics. In Modern Diuretic Therapy in the Treatment of Cardiovascular and Renal Disease. A. F. Lant, and G. M. Wilson, editors. Excerpta Medical, Amsterdam. $97-111$.

15. Jacob, H. S., and T. Amsden. 1971. Acute hemolytic anemia with rigid red cells in hypophosphatemia. $N$. Engl. J. Med. 285: 1446-1450.

16. Lichtman, M. A., D. R. Miller, J. Cohen, and C. Waterhouse. 1971. Reduced red cell glycolysis, 2,3-diphosphoglycerate and adenosine triphosphate concentration and increased hemoglobin-oxygen affinity caused by hypophosphatemia. Ann. Intern. Med. 74: 562-568.

17. Craddock, P. R., Y. Yawata, L. VanSanten, S. Gilberstadt, S. Silvis, and H. S. Jacob. 1974. Acquired phagocyte dysfunction. A complication of the hypophosphatemia of parenteral hyperalimentation. N. Engl. J. Med. 290: 1403-1407.

18. Klock, J. C., H. E. Williams, and W. C. Mentzer. 1974. Hemolytic anemia and somatic cell dysfunction in severe hypophosphatemia. Arch. Intern. Med. 134: 360-364.

19. Fuller, T. J., N. W. Carter, C. Barcenas, and J. P. Knochel. 1976. Reversible changes of the muscle cell in experimental phosphorus deficiency. J. Clin. Invest. 57: 10191024.

20. Yawata, Y., P. Craddock, R. Hebbel, R. Howe, S. Silvis, and H. Jacob. 1973. Hyperalimentation hypophosphatemia: hematologic-neurologic dysfunction due to ATP depletion. Clin. Res. 21: 729. (Abstr.)

21. Potts, J. T., Jr., R. M. Buckle, L. M. Sherwood, C. F. Ramberg, Jr., C. P. Mayer, D. S. Kronfeld, L. J. Deftos, A. D. Care, and G. D. Aurbach. 1968. Control of secretion of parathyroid hormone. In Parathyroid Hormone and Thyrocalcitonin (Calcitonin). R. V. Talmage and L. F.
Bélanger, editors. Excerpta Medica, Amsterdam. 407416.

22. Agus, Z. S., P. J. S. Chiu, and M. Goldberg. 1975. Role of the terminal nephron in regulation of urine calcium and sodium excretion: site of action of volume expansion and parathyroid hormone (PTH). Clin. Res. 23: 428A. (Abstr.)

23. Coburn, J. W., D. L. Hartenbower, and S. G. Massry. 1971. Modification of calciuretic effect of extracellular volume expansion by phosphate infusion. Am.J. Physiol. 220 (2): $377-383$.

24. Lemann, J., Jr., J. R. Litzow, and E. J. Lennon. 1967. Studies of the mechanism by which chronic metabolic acidosis augments urinary calcium excretion in man. J. Clin. Invest. 46: 1318-1328.

25. Emmett, M., S. Goldfarb, Z. S. Agus, and R. G. Narins. 1977. The pathophysiology of acid-base changes in chronically phosphate depleted rats: bone-kidney interactions. J. Clin. Invest. 59: 291-298.

26. Buckalew, V. M., Jr., D. K. McCurdy, G. D. Ludwig, L. B. Chaykin, and J. R. Elkinton. 1968. Incomplete renal tubular acidosis. Physiologic studies in three patients with a defect in lowering urine pH. Am.J. Med. 45: $32-42$.

27. Ben-Isaac, C., S. G. Massry, S. Rosenfeld, C. R. Kleeman, and M. Beck. 1975. Evidence for humoral factor responsible for the hypercalciuria ( $\uparrow \mathrm{UCaV})$ of phosphate depletion (PD). Clin. Res. 23: 134A. (Abstr.)

28. Steele, T. H., and H. F. DeLuca. 1976. Influence of dietary phosphorus on renal phosphate reabsorption in the parathyroidectomized rat. J. Clin. Invest. 57: 867-874.

29. Wen, S. F. 1975. Phosphate transport in the phosphatedepleted dog. Kidney Int. 8: 405. (Abstr.)

30. Shen, F., D. Baylick, R. Nielsen, D. Sherrard, and M. Haussler. 1976. A study of the pathogenesis of idiopathic hypercalciuria. Clin. Res. 24: 460A. (Abstr.) 